\title{
Organocatalyzed Photoelectrochemical C-H Amination of Arenes
}

\author{
Zhong-Wei Hou, ${ }^{[a, b]}$ Hong Yan, ${ }^{[a]}$ Jinshuai Song ${ }^{[c]}$ and Hai-Chao Xu*[a] \\ ${ }^{[a]}$ Key Laboratory of Chemical Biology of Fujian Province, State Key Laboratory of Physical Chemistry of Solid Surfaces, and College of Chemistry and Chemical \\ Engineering Xiamen University, Xiamen 361005 (China) \\ ${ }^{[b]}$ Advanced Research Institute and Department of Chemistry, Taizhou University, Taizhou 318000 (China) \\ ${ }^{[c]}$ Green Catalysis Center, and College of Chemistry, Zhengzhou University, Zhengzhou 450001 (China)
}

\begin{abstract}
Catalytic $\mathrm{C}-\mathrm{H} / \mathrm{N}-\mathrm{H}$ cross-coupling is considered an ideal strategy for accessing anilines and derivatives, but its synthetic execution remains extremely challenging, especially when the exclusion of external oxidants is desired. Report herein is a photoelectrochemical method for the preparation of anilides through $\mathrm{C}-\mathrm{H} / \mathrm{N}-\mathrm{H}$ coupling of arenes and carbamates, which employs $\mathrm{DDQ}$ as a molecular catalyst. The reactions are conducted in a simple undivided cell with visible-light irradiation and without any need for external chemical oxidants. In addition, the reactions employ arenes as the limiting agent, and are compatible with benzene and halogenated benzenes.
\end{abstract}

Aniline and its derivatives are essential precursors to pharmaceuticals, agrochemicals, and high-performance materials. Among the synthetic strategies available, direct $\mathrm{C}_{-}$ $\mathrm{H} / \mathrm{N}-\mathrm{H}$ cross-coupling of arene with a nucleophilic nitrogen source is straightforward and highly attractive. ${ }^{[1]}$ Ideally, these reactions should proceed via $\mathrm{H}_{2}$ evolution without using external oxidants. $^{[2,3]}$ In this context, Yoshida and coworkers have reported an intriguing cation-pool method that achieves aniline production through amination with pyridine in a divided cell, followed by reaction with piperidine (Scheme 1a). ${ }^{[4]}$ Lei and coworkers have developed an electrochemical $\mathrm{C}-\mathrm{H}$ amination reaction of arenes with acidic sulfonimides via $\mathrm{N}$-radical addition (Scheme 1a). ${ }^{[5]}$ The sulfonyl groups can be reductively removed with $\mathrm{Mg}$ and $\mathrm{Ti}(\mathrm{O}-\mathrm{Pr})_{4}$ to obtain free anilines. The direct $\mathrm{C}-\mathrm{H}$ amination with tert-butyl carbamate $\left(\mathrm{BocNH}_{2}\right)$ is an appealing route to anilines, considering that tert-butyloxycarbonyl (Boc) is the most desirable protecting group for amines due to its ease of removal. However, an efficient catalytic method to accomplish such dehydrogenative cross-coupling remains elusive. ${ }^{[6]}$

Others and us have recently reported the merger of organic electrochemistry with molecular photochemistry for the development of new methodologies..$^{[7,8]}$ In this context, Lambert and coworkers ${ }^{[8 \mathrm{~b}, \mathrm{c}]}$ published elegantly executed transformations of azoles with excessive arenes via $\mathrm{C}-\mathrm{H} / \mathrm{N}-\mathrm{H}$ cross-coupling or $\mathrm{S}_{\mathrm{N}} \mathrm{Ar}$, employing a novel trisaminocyclopropenium ion or the well-established photooxidant 2,3-dichloro-5,6-dicyano-1,4benzoquinone $(\mathrm{DDQ})^{[9]}$ as molecular photoelectrocatalyst. Although the use of such catalysts, whose excited states are highly oxidizing with $E_{\text {red }}>3 \mathrm{~V}$ vs SCE, allows the reaction to be compatible with electron-neutral and mildly electron-deficient arenes, the acidic conditions prevent the use of acid sensitive Boc $\mathrm{NH}_{2}$ as the coupling partner for aniline synthesis. Here we report an unprecedented DDQ-catalyzed photoelectrochemical C-H amination reaction of arenes with carbamates (Scheme 1b) These reactions employ the arene as the limiting agent and are conducted in the absence of acidic or basic additives with low concentration of electrolyte. Importantly, halogenated arenes are suitable for the $\mathrm{C}-\mathrm{H}$ amination reaction.

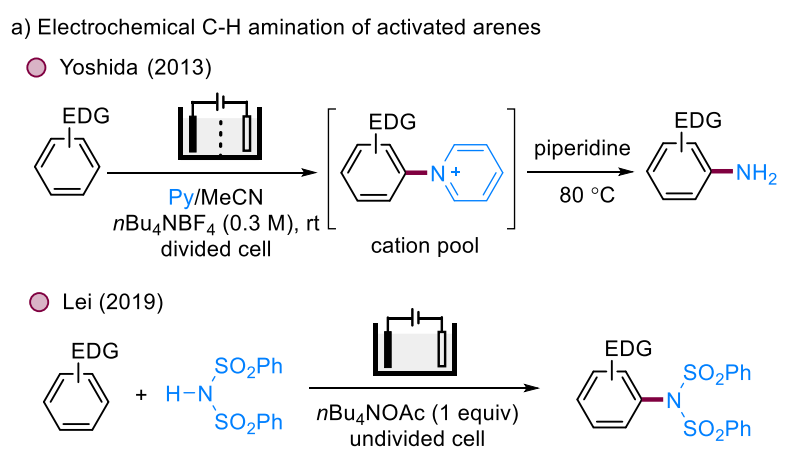

b) $\mathrm{C}-\mathrm{H}$ amination of unactivated arenes via molecular photoelectrocatalysis (this work)

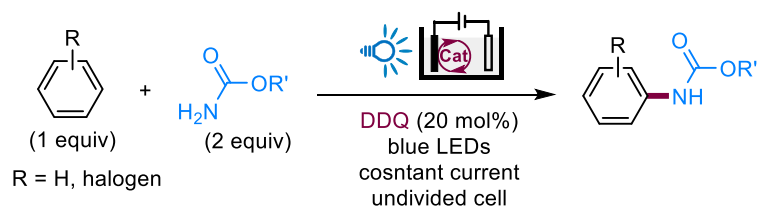

Scheme 1. Synthesis of aniline and derivatives through $\mathrm{C}-\mathrm{H}$ amination.

We first explored the $\mathrm{C}-\mathrm{H}$ amination of benzene (1) with $\mathrm{BocNH}_{2}$ (2). The photoelectrochemical reaction was conducted in an undivided cell at a constant current and under the irradiation of blue LEDs (Table 1). The optimal conditions turned out to be simple, involving DDQ (20 mol\%) as a molecular catalyst and a low concentration of $\mathrm{Et}_{4} \mathrm{NBF}_{4}$ ( 0.1 equiv) as electrolyte, in a solvent of MeCN. Under these conditions, the desired anilide 3 was obtained in $83 \%$ yield (entry 1 ) with no detection of multi-amination products. Control experiments revealed that the lack of light irradiation (entry 2) or catalyst (entry 3) completely abolished the reaction, whereas the exclusion of electricity (entry 4) resulted in the isolation of a very low amount of 2 , which we speculated was attributable to residual oxygen and the added DDQ. Oxygen tolerance was demonstrated by the fact that running the reaction under air also furnished 2 in $82 \%$ yield (entry 5). Lowering the amount of catalyst to $10 \mathrm{~mol} \%$ (entry 6 ) or that of the amination agent to 1.5 (entry 7 ) or 1.1 equiv (entry 8 ) resulted in diminished product formation.

Halogenated arenes are more difficult to oxidize than benzene, but contain $\mathrm{C}$-halogen bonds as versatile synthetic handles. To our gratification, our method showed good tolerance for an array of di- and mono-halogenated benzenes, with the 
preferred site of amination generally being that para to the halogen substituent (Scheme 2). For example, 1,2-dichloro and 1,2-dibromobenzene afforded the corresponding monoamination products 4 and $\mathbf{5}$, respectively, in a regioselective manner and in good yields. Similarly, neither the amination of 1,3-dichloro- (6) nor that of 1,3-dibromobenzene (7) generated any other regioisomers. Mixed dihalobenzenes such as 1-chloro2-fuorobenzene (8) and 1-bromo-2-chlorobenzene (9) also reacted preferentially at the site para to the halogen, but with moderate or no regioselectivity. Mono-halogenated benzenes such as fluoro-, chloro- and bromobenzene reacted at para- and meta-positions to furnish the corresponding mono-amination products (10-12). While the amination of fluorobenzene exhibited no para/meta selectivity, the chloro- and bromobenzenes predominately afforded the para regioisomer. Methyl benzoate (13), however, failed to afford any amination product probably due to its high oxidation potential. Notably, electron-rich arenes such as anisole (14) also failed to react with BocNH ${ }_{2}$ due to both the reduced reactivity of the corresponding arene radical cation and rapid back-electron transfer. ${ }^{[9]}$ Such a reactivity pattern also ensured mono-amination during the photoelectrochemical reaction that employed arene as the limiting agent.
Table 1. Optimization of reaction conditions. ${ }^{[a]}$

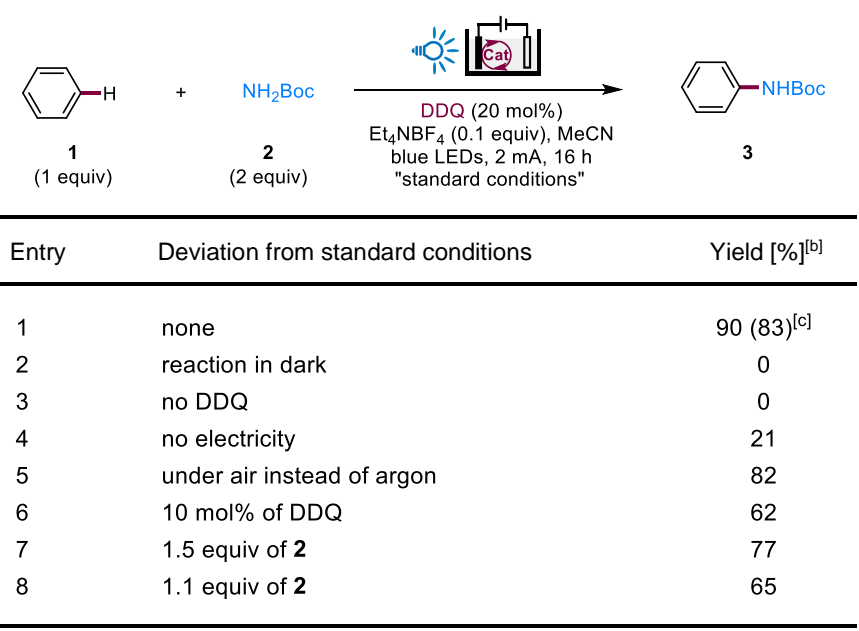

[a] Reaction conditions: 1 (0.5 mmol), MeCN (6 mL), argon, blue LEDs (450 $\mathrm{nm}$ ), undivided cell (RVC anode, Pt plate cathode), $2.4 \mathrm{~F} \mathrm{~mol}^{-1}$. [b] Determined by ${ }^{1} \mathrm{H}$ NMR analysis using 1,3,5-trimethoxybenzene as an internal standard. [c] Isolated yield in parenthesis.

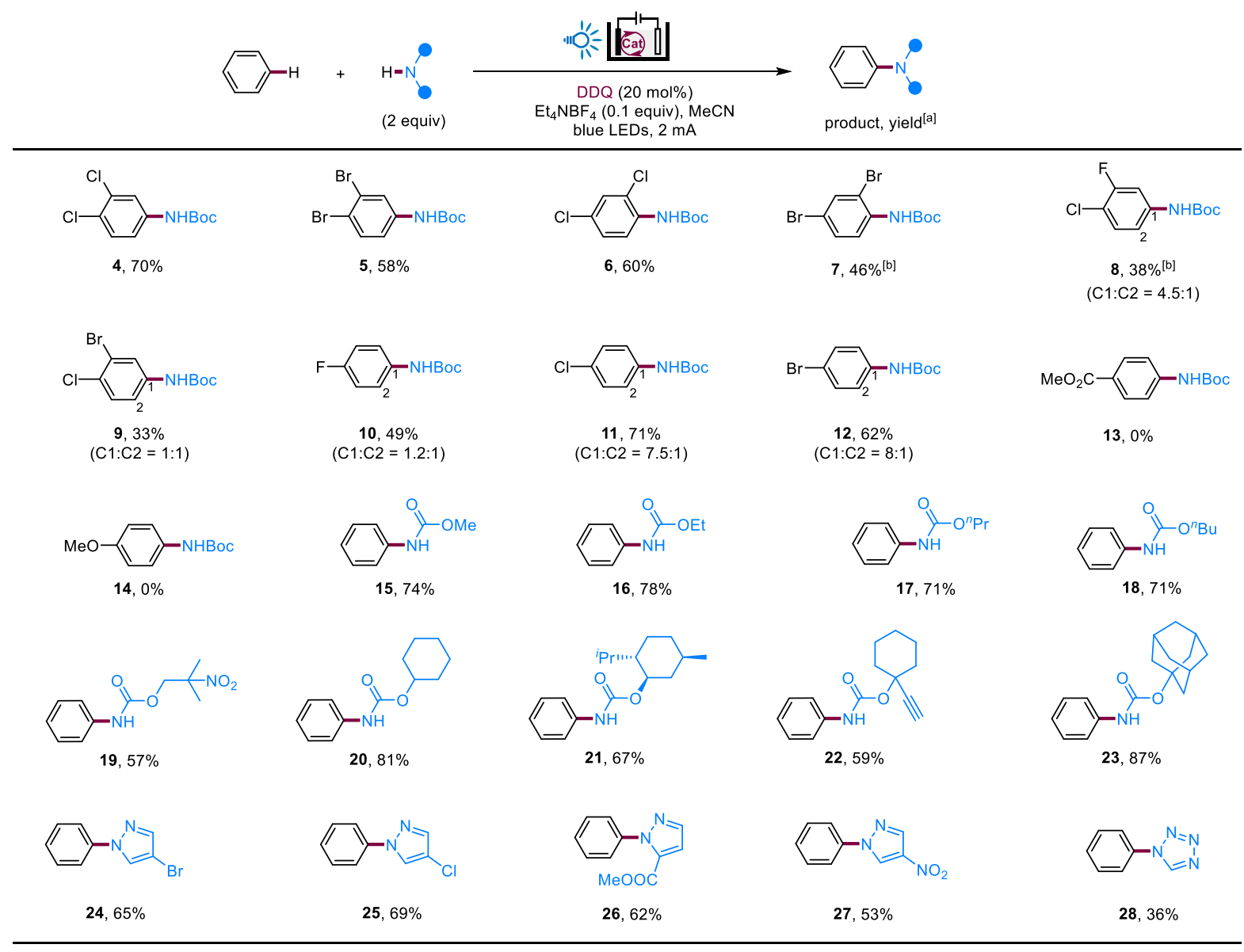

Scheme 2. Reactions were conducted at $0.5 \mathrm{mmol}$ scale in $\mathrm{MeCN}(6 \mathrm{~mL}), 2.4 \mathrm{~F} \mathrm{~mol}^{-1}$. [a] Isolated yield. [b] Reaction using a constant current of $4 \mathrm{~mA}$ for $16 \mathrm{~h}$ $\left(4.8 \mathrm{~F} \mathrm{~mol}^{-1}\right)$ with $\mathrm{Et}_{4} \mathrm{NBF}_{4}(0.5$ equiv) as electrolyte.

Besides $\mathrm{BocNH}_{2}$, several other alkyl carbamates of different steric properties reacted smoothly with benzene to generate the corresponding anilides in good yields (15-23). This photoelectrocatalytic method is also applicable to $\mathrm{C}-\mathrm{H}$ amination 
with azoles (24-28), ${ }^{[8 b, 10]}$ which are more nucleophilic than carbamates.

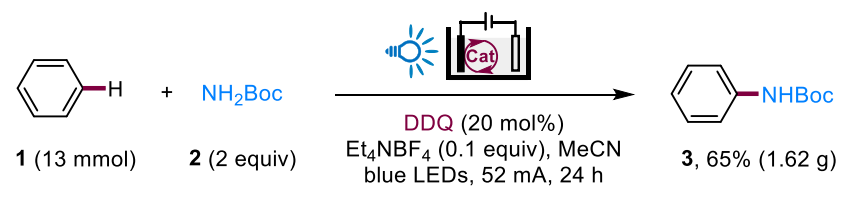

Scheme 3. Gram scale synthesis of $\mathbf{3}$.

The photoelectrochemical $\mathrm{C}-\mathrm{H}$ amination reaction can be conducted on a gram scale, as demonstrated by the synthesis 1.62 grams of $\mathbf{3}$ in $65 \%$ yield (Scheme 3 ). Larger electrodes were employed to increase current output for a shorter reaction time.

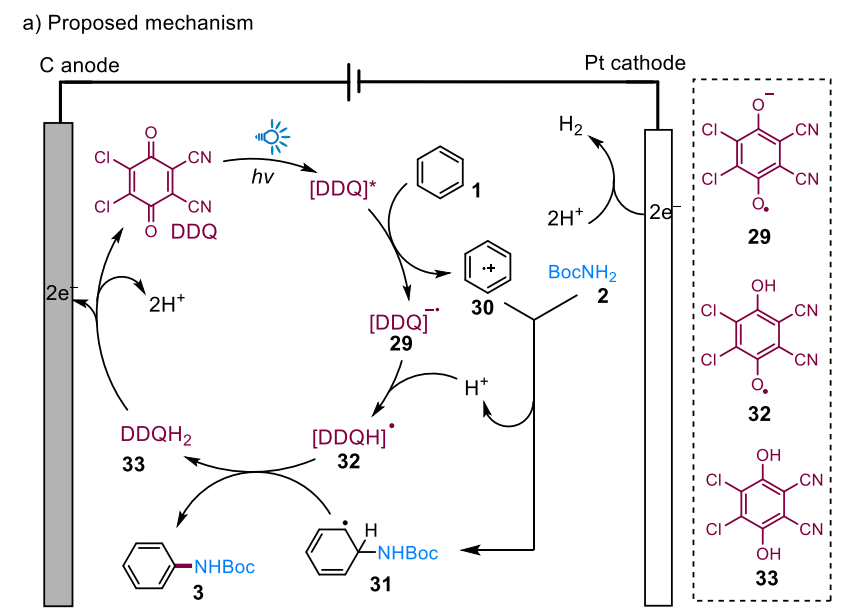

b) DFT calculated LUMO of arene radical cations

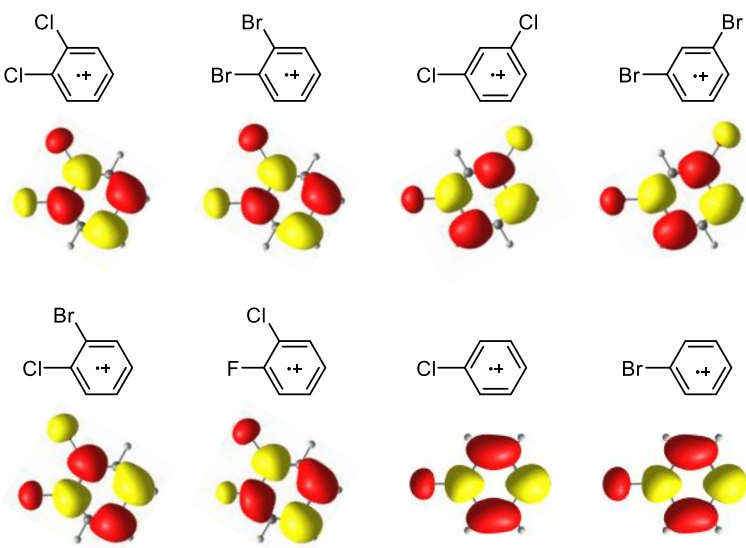

Scheme 4. Mechanistic proposal and DFT calculations (M06-2X/6-31G*).

A possible mechanism for the photoelectrocatalytic $\mathrm{C}-\mathrm{H}$ amination reaction is proposed based on the reaction of benzene and $\mathrm{BocNH}_{2}$ (Scheme $4 \mathrm{a}$ ). Photoexcitation of DDQ leads to a highly oxidizing excited state $[D D Q]^{*}\left(E^{*}\right.$ red $=3.18 \mathrm{~V}$ vs $\mathrm{SCE}),{ }^{[9]}$ which is then reduced by benzene to generate a persistent radical anion $\mathbf{2 9}$ and a reactive arene radical cation $\mathbf{3 0}$ The latter is trapped by BocNH ${ }_{2}$ to generate cyclohexadienyl radial 31 after proton loss. Radical anion 29 picks the proton and abstracts a hydrogen atom from $\mathbf{3 1}$ to generate hydroquinone $\mathbf{3 3}$ and furnish the final amination product $\mathbf{3}$. $\mathbf{3}$ is oxidized at a lower potential than benzene, but does not undergo further amination because of the reduced reactivity of 3-derived radical cation and its rapid back-electron transfer with 29.

The lowest unoccupied molecular orbital (LUMO) of radical cations of few halogenated benzenes were obtained by DFT calculations and showed higher distribution at the positions para to the halogens than other locations (Scheme 4b). These theoretical results are consistent with the observed regioselectivity of the $\mathrm{C}-\mathrm{H}$ amination reaction.

In summary, we have developed an oxidant-free, catalytic approach for the $\mathrm{C}-\mathrm{H}$ amination of arenes with carbamates via molecular photoelectrocatalysis. The highly oxidative potential of the excited state of DDQ allows the synthesis of Boc-protected anilines directly from unactivated arenes such as benzene and halogenated benzenes.

\section{Acknowledgements}

The authors acknowledge the financial support of this research from NSFC (21971213), MOST (2016YFA0204100), China Postdoctoral Science Foundation (2018M630730), and Fundamental Research Funds for the Central Universities. J.S. thanks the Henan Province Supercomputing Center.

\section{Conflict of interest}

The authors declare no conflict of interest.

Keywords: electrochemistry • photocatalysis • photoelectrocatalysis $\cdot \mathrm{C}-\mathrm{H}$ amination $\bullet$ aniline

[1] a) Y. Park, Y. Kim, S. Chang, Chem. Rev. 2017, 117, 9247-9301; b) V. S. Thirunavukkarasu, S. I. Kozhushkov, L. Ackermann, Chem Commun. 2014, 50, 29-39; c) N. A. Romero, K. A. Margrey, N. E. Tay, D. A. Nicewicz, Science 2015, 349, 1326-1330.

[2] H. Wang, X. Gao, Z. Lv, T. Abdelilah, A. Lei, Chem. Rev. 2019, 119, 6769-6787.

[3] Transition metal-catalyzed electrochemical $\mathrm{C}($ aryl)- $\mathrm{H}$ amination with directing group: a) S.-K. Zhang, R. C. Samanta, N. Sauermann, L. Ackermann, Chem. Eur. J. 2018, 24, 19166-19170; b) N. Sauermann, R. Mei, L. Ackermann, Angew. Chem. Int. Ed. 2018, 57, 5090-5094 Angew. Chem. 2018, 130, 5184-5188; c) X. Gao, P. Wang, L. Zeng, S. Tang, A. Lei, J. Am. Chem. Soc. 2018, 140, 4195-4199; d) Q.-L. Yang, X.-Y. Wang, J.-Y. Lu, L.-P. Zhang, P. Fang, T.-S. Mei, J. Am. Chem Soc. 2018, 140, 11487-11494.

[4] a) T. Morofuji, A. Shimizu, J. Yoshida, J. Am. Chem. Soc. 2013, 135 5000-5003; b) L. J. Wesenberg, S. Herold, A. Shimizu, J. Yoshida, S. R. Waldvogel, Chem. Eur. J. 2017, 23, 12096-12099.

[5] X. Hu, G. Zhang, L. Nie, T. Kong, A. Lei, Nat. Commun. 2019, 10, 5467

[6] a) Y. W. Zheng, B. Chen, P. Ye, K. Feng, W. Wang, Q. Y. Meng, L. Z. Wu, C. H. Tung, J. Am. Chem. Soc. 2016, 138, 10080-10083; b) S. Das, P. Natarajan, B. König, Chem. Eur. J. 2017, 23, 18161-18165.

[7] For reviews: a) J. P. Barham, B. König, Angew. Chem. Int. Ed. 2020, 59, 11732-11747; Angew. Chem. 2020, 132, 11828-11844; b) L. Capaldo, L. L. Quadri, D. Ravelli, Angew. Chem. Int. Ed. 2019, 58, 17508-17510; Angew. Chem. 2019, 131, 17670-17672; c) Y. Yu, P. Guo, J.-S. Zhong, Y. Yuan, K.-Y. Ye, Org. Chem. Front. 2020, 7, 131-135; d) J. Liu, L. Lu, D. Wood, S. Lin, ACS Cent. Sci. 2020, 6, 1317-1340; e) T. H. Meyer, I. Choi, C. Tian, L. Ackermann, Chem 2020, 6, 2484-2496. 
[8] These methods employ molecular light-absorbers and simple electrodes as opposed to interfacial photoelectrochemistry that uses semiconductor photoelectrodes. Several terms have been used to describe this chemistry, including electrophotocatalysis, photoelectrocatalysis, electron-primed photoredox catalysis, and electrochemically mediated photoredox catalysis: a) F. Wang, S. S Stahl, Angew. Chem. Int. Ed. 2019, 58, 6385-6390; Angew. Chem. 2019, 131, 6451-6456; b) H. Huang, Z. M. Strater, M. Rauch, J. Shee, T. J. Sisto, C. Nuckolls, T. H. Lambert, Angew. Chem. Int. Ed. 2019, 58, 13318-13322; Angew. Chem. 2019, 131,13452-13456; c) H. Huang, T. H. Lambert, Angew. Chem. Int. Ed. 2020, 59, 658-662; Angew. Chem. 2020, 132, 668-672; d) H. Huang, Z. M. Strater, T. H. Lambert, J. Am. Chem. Soc. 2020, 142, 1698-1703; e) H. Kim, H. Kim, T. H. Lambert, S. Lin, J. Am. Chem. Soc. 2020, 142, 2087-2092; f) W. Zhang, K. L. Carpenter, S. Lin, Angew. Chem. Int. Ed. 2020, 59, 409-417; Angew. Chem. 2020, 132, 417-425; g) N. G. W. Cowper, C. P. Chernowsky, O P. Williams, Z. K. Wickens, J. Am. Chem. Soc. 2020, 142, 2093-2099; h) Y. Qiu, A. Scheremetjew, L. H. Finger, L. Ackermann, Chem. - Eur. J. 2020, 26, 3241-3246; i) L. Niu, C. Jiang, Y. Liang, D. Liu, F. Bu, R. Shi, H. Chen, A. D. Chowdhury, A. Lei, J. Am. Chem. Soc. 2020, 142 17693-17702; j) S. Wu; J. Zurauskas; M. Domanski; P. Hitzfeld; V. Butera; D. Scott; et al. ChemRxiv. Preprint. 2020 https://doi.org/10.26434 /chemrxiv. 13140053.v1; k) H. Yan, Z.-W. Hou H.-C. Xu, Angew. Chem. 2019, 131, 4640-4643; Angew. Chem. Int. Ed. 2019, 58, 4592-4595; I) P. Xu, P.-Y. Chen, H.-C. Xu, Angew. Chem. Int Ed. 2020, 59, 14275-14280; Angew. Chem. 2020, 132, 14381-14386 m) X. Lai, X. Shu, J. Song, H.-C. Xu, Angew. Chem. Int. Ed. 2020, 59 10626-10632; Angew. Chem. 2020, 132, 10713-10719.

[9] K. Ohkubo, A. Fujimoto, S. Fukuzumi, J. Am. Chem. Soc. 2013, 135 5368-5371.

[10] a) L. Niu, H. Yi, S. Wang, T. Liu, J. Liu, A. Lei, Nat. Commun. 2017, 8, 14226; b) L. Zhang, L. Liardet, J. Luo, D. Ren, M. Gratzel, X. Hu, Nat Catal. 2019, 2, 266-373. 